\title{
Ecosystem Stewardship: Sustainability Strategies for a Rapidly Changing Planet
}

\section{Citation}

Chapin, F. S., Stephen R. Carpenter, Gary P. Kofinas, et al. 2010. Ecosystem Stewardship: Sustainability Strategies for a Rapidly Changing Planet." Trends in Ecology \& Evolution. 25 (4): 241-249.

\section{Published Version}

http://dx.doi.org/10.1016/j.tree.2009.10.008

\section{Permanent link}

http://nrs.harvard.edu/urn-3:HUL.InstRepos:9774650

\section{Terms of Use}

This article was downloaded from Harvard University's DASH repository, and is made available under the terms and conditions applicable to Open Access Policy Articles, as set forth at http:// nrs.harvard.edu/urn-3:HUL.InstRepos:dash.current.terms-of-use\#OAP

\section{Share Your Story}

The Harvard community has made this article openly available.

Please share how this access benefits you. Submit a story.

Accessibility 
Chapin, F. S., Stephen R. Carpenter, Gary P. Kofinas, et al. 2010. Ecosystem stewardship: Sustainability strategies for a rapidly changing planet." Trends in Ecology \& Evolution. 25 (4):241-249.

\title{
Ecosystem Stewardship: Sustainability Strategies for a Rapidly Changing Planet
}

F. Stuart Chapin, III, Stephen R. Carpenter, Gary P. Kofinas, Carl Folke, Nick Abel, William C. Clark, Per Olsson, D. Mark Stafford Smith, Brian Walker, Oran R. Young, Fikret Berkes, Reinette Biggs, J. Morgan Grove, Rosamond L. Naylor, Evelyn Pinkerton, Will Steffen, Frederick J. Swanson

\begin{abstract}
Ecosystem stewardship is an action-oriented framework intended to foster social-ecological sustainability of a rapidly changing planet. Recent developments identify three strategies that make optimal use of current understanding in an environment of inevitable uncertainty and abrupt change: reducing the magnitude of, and exposure and sensitivity to, known stresses; focusing on proactive policies that shape change; and avoiding or escaping unsustainable socialecological traps. All social-ecological systems are vulnerable to recent and projected changes but have sources of adaptive capacity and resilience that can sustain ecosystem services and human well-being through active ecosystem stewardship.
\end{abstract}

\section{A Call for Ecosystem Stewardship}

Human actions are having large and accelerating effects on Earth's climate, environment, and ecosystems ${ }^{1,2}$, thereby degrading many ecosystem services (see glossary) ${ }^{3}$. This unsustainable 
trajectory demands a dramatic change in human relationships with the environment and lifesupport system of the planet ${ }^{2,3}$. In this paper we address recent developments in thinking about the sustainable use of ecosystems and resources by society in the context of rapid and frequently abrupt change (Box 1).

Western resource management paradigms have evolved from exploitation, where sustainability is not an important consideration, to steady-state resource management aimed at maximum or optimum sustainable yield (MSY or OSY, respectively) and efficient production of a single resource such as fish or trees, to ecosystem management to sustain a broader suite of ecosystem services ${ }^{4}$ (Fig. 1). Despite its sustainability goal, management for MSY or OSY tends to over-exploit targeted resources because of overly optimistic assumptions about the capacity to sustain productivity, avoid disturbances, regulate harvesters' behavior, and anticipate extreme economic or environmental events ${ }^{5}$. Ecosystem management seeks to sustain multiple ecosystem services ${ }^{6}$ but often uses, as a reference point, historic conditions that are not achievable in a rapidly changing world.

Given the challenges of sustainable use of ecosystems during rapid change, we advocate a shift to ecosystem stewardship (Table 1$)^{7,8}$. Its central goal is to sustain the capacity to provide ecosystem services that support human well-being under conditions of uncertainty and change (see glossary). Uncertainty has always characterized social-ecological systems and should therefore not be an impediment to action. Such a paradigm shift entails important tradeoffs, particularly between efficiency and flexibility and between immediate and long-term benefits 9 , 10

Ecosystem stewardship integrates three broadly overlapping sustainability approaches ${ }^{8,}$ 11,12 (Fig. 2): reducing vulnerability to expected changes ${ }^{11-13}$; fostering resilience to sustain 
desirable conditions in the face of perturbations and uncertainty ${ }^{14}$; and transforming from undesirable trajectories when opportunities emerge ${ }^{15,16}$. Adaptive capacity contributes to all three sustainability approaches ${ }^{8,17}$. By building on previous research on vulnerability, adaptation, resilience, and transformation (see glossary), ecosystem stewardship provides a perspective that better equips society to manage a spectrum of challenges that vary in certainty and benefit or threat to society. The need is to identify pragmatic strategies that increase the likelihood of socially beneficial outcomes and reduce the risk of bad outcomes. This approach is explicitly focused on human norms, values, and well-being and must therefore continually be debated and reassessed by stakeholders.

\section{Assessing and Reducing Vulnerability to Known Stresses}

Reducing exposure or sensitivity to currently recognized stresses such as drought, overgrazing, and pest outbreaks is standard practice in sound resource management (Box 2). Local managers generally know the identity of historically important stresses and specific adaptation options that successfully reduced system vulnerability in the past. More comprehensive vulnerability analyses identify the stresses most likely to cause harm and the segments of society that are particularly vulnerable ${ }^{11}$. By monitoring trends in these stressors and their impacts, resource users can gauge changes over time and act to reduce stresses or exposure to stresses. For example, overgrazing in drylands reduces the abundance of palatable plants, indicating the need to reduce grazing pressure ${ }^{18}$. Similarly, monitoring of snowpack provides a sound basis for predicting water shortages and planning water allocations for the following summer. Impacts are, however, often masked by interactions and feedbacks, such as lake-sediment sequestration of 
phosphorus that returns to the water column after some threshold is exceeded ${ }^{19}$ or subsidies to fishing fleets to maintain catch levels and incomes of fishermen despite stock declines ${ }^{20}$. Impacts can also be masked by high variability in system drivers, such as variable rainfall in arid rangelands ${ }^{21}$. Detecting social-ecological impacts therefore requires ecosystem and social indicators that are sensitive to slowly changing causes and initial phases of degradation ${ }^{22}$.

Global-scale stresses, such as climate change, international fishing pressure, and demand for biofuels, are particularly challenging because local actions sometimes reduce exposure to the stresses (e.g. sea walls that reduce exposure to sea level rise), but seldom reduce the magnitude of stress. Reducing global stresses requires concerted global action, for which governance mechanisms are currently inadequate ${ }^{23,24}$. Although collaboration among a few key nations can sometimes reduce global-scale stresses (e.g. industrialized nations banning ozone-destroying chlorofluorocarbons in the Montreal Protocol), incentives that entrain most nations are more effective $^{25}$.

For stresses that persist, trajectories of expected change are more appropriate management targets than are historical states or ranges of variability ${ }^{26}$. New York City, for example, is planning phased infrastructure replacement to accommodate a $1.2 \mathrm{~m}$ sea-level rise (greater than IPCC projections that ignore potential melting of ice sheets) rather than historical sea level (http://www.nyc.gov/html/planyc2030/).

Social-ecological vulnerability also depends on sensitivity to known risks. Policies that constrain development in risky places such as floodplains or fire-prone wildland-urban interfaces, for example, reduce human vulnerability to environmental disasters. Expected future changes in sea level have led to 'dynamic rezoning' (strategic retreat) in coastal Australia. Interventions targeting segments of society that are most vulnerable to a given stress can reduce 
net social impacts of shocks and stresses ${ }^{11,27-29}$. For example, urban heat-wave warning systems that target the elderly or poor people living in poorly ventilated housing are most effective in

minimizing heat-related mortality ${ }^{30}$. In general, programs that build and sustain natural, human, and social capital and broaden the range of livelihood opportunities reduce society's vulnerability to a broad range of stresses ${ }^{3,11}$ (Fig. 2, Box 2).

Reasons for inaction to reduce known vulnerabilities include institutional mismatch to the scale at which stresses are generated, costs of reduction that are perceived to exceed benefits, lack of resources, and tradeoffs among segments of society and across generations ${ }^{3,11,31}$. In summary, although reducing vulnerability to known stresses is not simple, the broad strategies described above for assessing and reducing vulnerability to current and projected changes are well-defined and tested: Identify the stresses and risks and their projected changes; reduce their magnitude; and reduce social-ecological exposure and sensitivity to these stresses.

\section{Proactive Strategies to Shape Uncertain Change}

Society is increasingly faced with changes that are unexpected or uncertain, often leading to a paralysis of indecision. Ecosystem stewardship shifts the resource-management philosophy from reactions to observed changes to proactive governance that shapes change for sustainability, while preparing for the unexpected ${ }^{8}$. This is analogous to a business strategy that shapes markets to sustain or develop competitive advantage in a changing and uncertain economic climate. We outline three suites of strategies for responding to and shaping uncertain change. These involve maintaining a diversity of options, enhancing social learning to facilitate adaptation, and adapting governance to implement potential solutions (Box 3). Not surprisingly, the ecosystem 
stewardship strategies for addressing uncertain change are less proven than those that address vulnerability to known stresses.

\section{Maintaining a Diversity of Options}

Socio-economic and biological diversity enhance the number of options for responding to and shaping change. Society often deliberately chooses low-diversity options, such as single-species production forests or an economy largely based on a single industry, because these can be managed efficiently, as long as the conditions supporting their productivity persist. A region whose economy depends entirely on one extractive industry, however, is poorly buffered against market fluctuations or technological innovations that reduce the value of that product. Policy incentives for innovation can generate economic diversity that enhances adaptability. This broadens the range of conditions for economic vitality and reduces the likelihood of economic booms and busts. In contrast, policy incentives that sustain uneconomical practices, such as overfishing of otherwise uneconomic stocks, reduce adaptability.

Just as with economic systems, an ecosystem whose species have a narrow range of functional properties (e.g. only palatable grasses) or a narrow range of environmental responses (e.g. only high water- and nutrient-requiring species) has a limited capacity to adjust to change (response diversity) and to sustain ecosystem services (functional diversity) compared to an

ecosystem with greater functional and response diversity ${ }^{32,33}$. For example, other things being equal, a mixed cropping system is less risky than a monospecific crop, and a grassland with both cool-season and warm-season grasses maintains productivity over a broader range of conditions than a grassland with one grass type, even though the latter may be more productive under 
favorable conditions. Farmers in developing nations that lack access to predictable subsidies often prefer cropping strategies that reduce risk of crop failure over those that optimize production under good conditions ${ }^{34}$. When the functional and response properties of most species are poorly known, as in most ecosystems, protection of biodiversity in general provides insurance that important ecosystem services will be sustained in the face of uncertain changes ${ }^{35}$. The ecological value of functional and response diversity is well documented in low-diversity ecosystems, where species invasions or loss substantially alter ecosystem services ${ }^{36}$. However, little is known about the relationship between magnitude and types of diversity and reductions in risk of functional changes in highly diverse systems ${ }^{36,37}$, where the greatest conservation concerns are focused.

Sometimes biodiversity reflects underlying topographic or substrate variability and will likely support future diversity, even if species composition were to change radically. Geographic juxtaposition in these areas allows species to adjust naturally to climatic change without the need to address the highly contested topic of assisted migration ${ }^{38}$. Urban green spaces and mobile species that link these habitats (e.g. pollinators and concerned gardeners) sustain diversity in human-dominated landscapes where society's connection to nature is most tenuous ${ }^{39}$. Involvement of local residents in conservation efforts in ways that support their livelihoods increases the likelihood that policies will be respected (Box 1) ${ }^{40}$.

Maintaining biodiversity entails tradeoffs. People deliberately reduce genetic, stand, and landscape diversity to enhance the productivity or harvest efficiency of a particular ecosystem service such as an agricultural or forestry crop under a narrow range of environmental and economic conditions. These short-term benefits generate longer-term vulnerabilities when market, pest, and environmental conditions change more rapidly than biotic composition, as 
might occur with long-lived forest species or agricultural practices that are culturally entrained. Tradeoffs evaluated only on economic terms generally use discount rates that limit the planning horizon to 1-2 decades and are blind to equity concerns, thereby limiting their usefulness in assessing social-ecological sustainability.

The last several centuries have substantially reduced the planet's cultural diversity ${ }^{41}$. Colonization forcibly removed indigenous people from their homelands, so colonizers could claim the resources ${ }^{42}$. During the mid- $20^{\text {th }}$ century, cultural assimilation further undermined cultural integrity through loss of language, local institutions, and cultural ties to the land and sea. Cultural diversity, particularly as mediated by language, provides multiple knowledge systems and perspectives on ways to meet societal goals ${ }^{43}$. On the other hand, cultural diversity in the short term can reduce civil engagement (e.g. voting, volunteerism, and neighborly trust) ${ }^{44}$. Rural-urban migration or relocation of people in response to wars or climate-related disasters can create tensions to which these new mixes of cultures are poorly adapted.

\section{Enhance Social Learning to Facilitate Adaptation}

Although diversity provides the raw materials for adaptation, social learning through experimentation, innovation, and knowledge sharing are the core processes that build the human dimensions of adaptive capacity and resilience of social-ecological systems ${ }^{45,46}$. This is well recognized by business ${ }^{47}$ and is particularly important under conditions of non-linear, abrupt, and irreversible social-ecological change. How can society shift from a mindset of fearing change to assessing its value in coping with and realizing new opportunities in a rapidly changing world? 
An obvious starting point is to broaden the framework of problem definition by integrating a broad range of disciplines, knowledge systems, user groups, and approaches. Resource managers, for example, moved from the management of single species such as pine or tuna to ecosystem management by acknowledging the importance of a broader range of ecosystem services and the key linkages between biophysical and social processes ${ }^{6}$. This shift required a broadening of institutional goals to recognize the legitimacy of multiple user groups who value multiple ecosystem services. In contrast, private landholders motivated primarily by profit might choose to manage their lands for a single ecosystem service (e.g. timber) unless incentive structures are modified (e.g. tax benefits for conservation easements).

Knowledge of how to cope with historical conditions is often insufficient in a rapidly changing world. Scenario building is one way to explore future conditions that cannot be readily predicted, envision potential futures, and explore alternative pathways to desired ends ${ }^{48}$. For example, by exploring alternative future water policy scenarios, the discourse about development in poor countries can be expanded beyond short-term responses into measures that increase land productivity, incomes, and household food security ${ }^{49}$. Comparisons of scenarios often highlight the tradeoffs and synergies between present and future generations or among stakeholders that might be less evident when a more limited suite of options is considered.

Much can be learned through comparative analysis of institutions and management systems in different social-ecological settings ${ }^{3,9}$, for example through comparative studies of common pool resources such as water, timber, and fish ${ }^{29}$. These comparative analyses enable us to learn from past unplanned social-ecological experiments and to define conditions that minimize risks of future planned social-ecological experiments. Comparative studies and systematic observations require information systems at relevant scales for conducting 
assessments, generating scenarios, and informing decision making. For example, GIS-based systems to monitor multiple indicators in nearly real-time enable cities to develop dialogues with stakeholders, design effective tactics and strategies, rapidly deploy resources, and facilitate follow-up (http://www.baltimorecity.gov/news/citistat/). This enables managers and planners to assess outcomes in a timely manner and to adaptively adjust conditions that will influence further changes.

Deliberate management experiments that perturb the current system provide learning opportunities that are particularly valuable when future environmental and economic conditions are uncertain. The Northwest Forest Plan in the northwestern U.S., for example, established a suite of harvest strategies ranging from uncut forests to intensive industrial-scale logging ${ }^{50}$. Even if a "best policy" could be identified for today's conditions, other policies might prove more favorable as an uncertain future unfolds ${ }^{51}$. In other cases, such as marine fisheries, policies often result more from political than scientific processes ${ }^{20}$. Managers are usually reticent to experiment with ecosystems or livelihoods because they face the blame for unfavorable outcomes. We can, however, compare outcomes where local managers are empowered to make different locally appropriate decisions in response to regional variation in conditions or social values.

Management that allows or fosters disturbance is often controversial ${ }^{5}$. Purchase of conservation easements that prevent residential development in rural scenic areas can, however, increase tolerance for wildfire as a natural ecological process in forests. Allowing large corporations to fail during economic crises provides space for innovation and adjustment to shifting economic opportunities. Such management that fosters change at one scale might enhance resilience at a broader scale, as in the two cases above. 
Adaptive management views management actions as experiments in which outcomes inform later policy choices. However experiments at large scales risk unanticipated outcomes that are beyond the control of managers to reverse. Current "experiments" with global climate and reductions in biological and cultural diversity are therefore of grave concern and require learning approaches that go beyond adaptive management.

\section{Adapting Governance to Implement Solutions}

Flexibility in governance to deal with change is critical to long-term social-ecological resilience and sustainability ${ }^{52,53}$. Distributing management powers and resources among organizations that operate at different spatial scales (polycentric governance) can enhance adaptability by creating functional redundancy through overlap in responsibilities ${ }^{16}$. State agencies, neighborhood groups, and national NGOs, for example, might all support actions that protect a valued species or habitat. Under static conditions, overlapping responsibilities create inefficiencies, jurisdictional tensions (turf wars), and time investments to negotiate shared responsibilities and create mutual understanding. In times of change, however, if one group "drops the ball" because of budget shortfalls or shifting priorities, the overlapping activities of other groups can sustain actions. Individuals and organizations such as NGOs or temporary public advocacy groups can provide informal communication networks that allow dialogue and negotiation to occur outside the rules and policies of formal institutions ${ }^{16}$. Polycentric governance, however, does not always work. Recent trends in decentralization of forest management, for example, driven by both economic shortfalls in central governments and well-intentioned efforts by NGOs to engage 
stakeholders in the governance process have had mixed success, with outcomes often dependent on local conditions and the governance tasks that are decentralized (and to whom) ${ }^{54,55}$.

Leadership is essential to effective governance, providing vision, social cohesion, and action $^{56,57}$. This can occur by re-conceptualizing issues, generating ideas and solutions, communicating across sectors and levels of governance, and recognizing or creating windows of opportunity ${ }^{58}$.

\section{Transforming to Potentially More Favorable Trajectories}

In the context of ecosystem stewardship, transformations involve forward-looking decisions to convert a system trapped in an undesirable state to a fundamentally different, potentially more beneficial system, whose properties reflect different social-ecological controls ${ }^{59}$ (Fig. 2). Socialecological transformations are always risky because, by definition, the changes are large, and the outcomes are uncertain, including potential capture by special interest groups. Transformational changes are important, however, to escape from persistent trajectories of poverty, hunger, civil strife, and social-ecological mismanagement that characterize so many parts of the world. The risks of unfavorable transformation outcomes can be minimized through careful planning by multiple user groups to assess the risks of good and bad outcomes; transparent navigation of the transformation process; and fostering resilience of those outcomes that meet broad societal goals. We summarize hypotheses for guiding transformation ${ }^{60-63}$ but they are currently unproven.

\section{Preparing for Transformation}


The first step in transformation is to identify plausible alternative trajectories and assess their desirability. This is challenging because most transformations create both winners and losers, have uncertain costs and benefits, and entail contentious decisions about allocation between present and future generations (Box 4). Stakeholder groups therefore often disagree about how serious the problems are and whether or how to fix them. The next step is to identify barriers to improvement (e.g. perverse incentives, inappropriate property rights, or corruption) and seek a collective vision for the future ${ }^{60,61}$. These are standard approaches in policy analysis ${ }^{64}$ and can be informed by using scenarios and clearly defining the social-ecological linkages ${ }^{65}$.

Examples of successful transformations include a shift away from Apartheid in South Africa and a shift from production forestry to ecosystem management in the northwestern U.S. 66. Traps that still require transformational rather than incremental solutions include persistent poverty in sub-Saharan Africa, failure to address climate change, and depletion of the planet's marine fish stocks ${ }^{3}$. Transformation to a potentially more beneficial state is the explicit goal of sustainable development programs in developing nations ${ }^{63}$.

\section{Navigating the Transition}

Transformational change is most likely to occur at times of crisis, when enough stakeholders agree that the current system is dysfunctional. Crises can lead to opportunities in at least three ways: active initiation of change, thus managing crisis and consequences; local system collapse, which raises broader awareness of the need for change; and learning from crises occurring at other times or places ${ }^{62}$. Despite inevitable power imbalances, transformational processes should be as transparent and open to all stakeholders as possible to counter attempts by particular groups 
to co-opt the outcome ${ }^{39}$. As a crisis deepens, stakeholders are more likely to negotiate a transformation.

Identification of potential crises provides the opportunity to plan for transformation opportunities. For example, increasing recognition of potentially "dangerous climate change" is a current crisis that could generate global technological and governance solutions. Because such planning and visioning seldom occur, the most common response to crisis is to rebuild the precrisis system rather than to attempt transformation (Fig. 2) ${ }^{67}$.

Informal networks of individuals operating outside conventional institutions often play an important role in seizing windows of opportunity to make use of abrupt change ${ }^{68,69}$. They can discuss and experiment with new approaches to uncertainty and change, unconstrained by organizational mandates ${ }^{16,68}$. An important challenge is to provide space for these networks to form through enabling legislation and financial, political, and moral support. The low frequency with which successful transformation occurs indicates that we still have much to learn about preparing for and navigating transformations (Box 4).

\section{Building Resilience of the New Governance System}

We suggest that successful transformation toward sustainability could be promoted by fostering innovation and building adaptive capacity and resilience (Boxes 3 and 4). The resilience of the new system might initially be fragile and can be strengthened by actions that foster respect, identify common social values among players of the new system, and empower key stakeholders to participate in decisions that legitimize relationships and interactions of the new regime. Building resilience under novel conditions often requires trust-building within newly formed 
collaborations. New patterns of winners and losers create tensions that are best resolved through transparent negotiations aimed at meeting broad societal goals and awareness of the agendas of competing interests. Transformations often alter the nature of cross-level interactions, providing both opportunities and challenges, including potentially different patterns of governance at other scales ${ }^{49,70}$. Shrinking arctic sea ice, for example, has dramatically altered the strategic and economic importance of the Arctic Ocean and therefore the potential roles of international treaties and organizations in addressing arctic change ${ }^{71}$. Early attention to cross-level interactions that ensure good information flow, systems of accountability, and sensitivity to differing perspectives reduces the likelihood of reversion to earlier or other unfavorable states ${ }^{72}$. Continuous evaluation and open discussion of costs and benefits of change provide opportunities to assess relatively undefined structures and relationships that arise in novel social-ecological situations.

In summary, there is a suite of approaches that increases the likelihood of successful transformation in governance of social-ecological systems ${ }^{16,68}$ (Box 4), but we currently have neither sufficient theory nor empirical evidence to identify their relative importance in the complex dynamics that play out in specific situations.

\section{Conclusions}

The specific issues that challenge ecosystem stewardship vary tremendously across the planet, so no single formula or institutional arrangement is applicable to all situations ${ }^{24,29}$. Nonetheless, several clear messages for research and implementation emerge from an ecosystem stewardship framework: 
- Ecosystem stewardship requires actions that recognize social-ecological interdependencies of human activities and ecosystem services.

- Every system exhibits critical vulnerabilities that become exacerbated as environmental and social changes push the system beyond its limits of adaptability. The nature of these vulnerabilities differs among social-ecological systems, but general strategies for reducing vulnerability are well established. The key challenges are promoting innovation and defining and negotiating the tradeoffs and synergies in specific situations.

- Every system has sources of socio-economic, biological, and institutional diversity that provide building blocks for adaptation to a rapidly changing but uncertain future. Social learning, manageable experimentation, and flexibility in governance facilitate this adaptation. General approaches to enhancing resilience are broadly recognized but seldom implemented in a concerted fashion.

- Every system has opportunities for transformation to alternative, potentially more desirable trajectories of social-ecological change. However, there is not yet a cohesive body of theory for avoiding undesirable thresholds and successfully navigating transformations to more desirable trajectories of change. This is a critical research need in our rapidly changing planet.

The science of ecosystem stewardship is sufficiently mature to make important contributions to all social-ecological systems. There is no region so resilient that policy makers and managers can ignore potential threshold changes ${ }^{73}$ or any region that is beyond hope of substantial enhancement of well-being, adaptive capacity, and resilience. Sustaining ecosystem services and livelihoods will, however, require reconnecting people's perceptions, values, 
institutions, actions, and governance systems to the dynamics of the biosphere through active ecosystem stewardship.

Acknowledgments: We thank the U.S. National Science Foundation (grant 0640638), the Resilience and Adaptation Program at the University of Alaska Fairbanks, the Beijer Institute of Ecological Economics, and the Stockholm Resilience Centre for supporting the Ecosystem Stewardship Project and workshop that developed this synthesis.

\section{References}

1. Haberl, H. et al. (2007) Quantifying and mapping the human appropriation of net primary production in Earth's terrestrial ecosystems. Proc. Natl. Acad. Sci. USA 104, 12942-12945

2. Foley, J.A. et al. (2005) Global consequences of land use. Science 309, 570-574

3. MEA (Millennium Ecosystem Assessment) (2005) Ecosystems and Human Well-being: Current Status and Trends. Cambridge University Press

4. Burton, P.J. et al. (2003) The current state of boreal forestry and the drive for change. In Towards Sustainable Management of the Boreal Forest (Burton, P.J., et al., eds), 1-40, National Research Council of Canada

5. Holling, C.S., and Meffe, G.K. (1996) Command and control and the pathology of natural resource management. Conserv. Biol. 10, 328-337

6. Christensen, N.L. et al. (1996) The report of the Ecological Society of America committee on the scientific basis for ecosystem management. Ecol. Appl. 6, 665-691 7. Berkes, F., et al. eds (2003) Navigating Social-Ecological Systems: Building Resilience for Complexity and Change. Cambridge University Press 
8. Chapin, F.S., III, et al. eds (2009) Principles of Ecosystem Stewardship: ResilienceBased Natural Resource Management in a Changing World. Springer

9. Liu, J. et al. (2007) Complexity of coupled human and natural systems. Science 317, $1513-1516$

10. Kareiva, P. et al. (2008) Development and conservation goals in World Bank projects. Science 321, 1638-1639

11. Turner, B.L., II et al. (2003) A framework for vulnerability analysis in sustainability science. Proc. Natl. Acad. Sci. USA 100, 8074-8079

12. Smit, B., and Wandel, J. (2006) Adaptation, adaptive capacity and vulnerability. Global Environ. Change 16, 282-292

13. Adger, W.N. (2006) Vulnerability. Global Environ. Change 16, 268-281

14. Folke, C. (2006) Resilience: The emergence of a perspective for social-ecological systems analysis. Global Environ. Change 16, 253-267

15. Walker, B. et al. (2004) Resilience, adaptability, and transformability in social-ecological systems. Ecol. Soc. 9, http://www.ecologyandsociety.org/vo19/iss2/art5

16. Folke, C. et al. (2005) Adaptive governance of social-ecological systems. Annu. Rev. Environ. Resources 30, 441-473

17. Adger, W.N. et al., eds (2009) Adapting to Climate Change: Thresholds, Values, Governance. Cambridge University Press

18. Walker, B. et al. (1999) Plant attribute diversity, resilience, and ecosystem function: The nature and significance of dominant and minor species. Ecosystems 2, 95-113

19. Carpenter, S.R. (2003) Regime Shifts in Lake Ecosystems: Pattern and Variation. International Ecology Institute 
20. Pauly, D. et al. (2005) Marine fisheries systems. In Ecosystems and Human Well-Being: Current State and Trends (Millennium Ecosystem Assessment, ed), 477-511, Island Press

21. Stafford Smith, D.M. et al. (2008) Learning from episodes of degradation and recovery in variable Australian rangelands. Proc. Natl. Acad. Sci. USA 104, 20690-20695

22. Gibson, R.B. (2005) Sustainability Assessment: Criteria and Processes. Earthscan

23. Ostrom, E. (2008) The challenge of common-pool resources. Environment 54, 10-20

24. Young, O.R. et al., eds (2008) Institutions and Environmental Change: Principal Findings, Applications, and Research Frontiers. MIT Press

25. Parson, E.A. (2003) Protecting the Ozone Layer: Science and Strategy. Oxford University Press

26. IPCC (2007) Climate Change 2007: The Physical Science Basis, Contribution of Working Group I to the Fourth Assessment Report of the Intergovernmental Panel on Climate Change. Cambridge University Press

27. Sachs, J.D. (2005) The End of Poverty: Economic Possibilities for Our Time. Penguin

28. Pinkerton, E.W., ed (1989) Co-operative Management of Local Fisheries: New

Directions for Improved Management and Community Development. University of British Columbia Press

29. Ostrom, E. (2007) A diagnostic approach for going beyond panaceas. Proc. Natl. Acad. Sci. USA 104, 15181-15187

30. Ebi, K.L. et al. (2004) Heat watch/warning systems save lives: Estimated costs and benefits for Philadelphia 1995-1998. Bull. Amer. Meteorol. Soc. 85, 1067-1073

31. Carpenter, S.R., et al. (2009) Science for managing ecosystem services: Beyond the Millennium Ecosystem Assessment. Proc. Natl. Acad. Sci. USA 106, 1305-1312 
32. Elmqvist, T. et al. (2003) Response diversity, ecosystem change, and resilience. Front. Ecol. Environ. 1, 488-494

33. Suding, K.N. et al. (2008) Scaling environmental change through the community level: A trait-based response- and-effect framework for plants. Global Change Biol. 14, 1125-1140

34. Naylor, R.L. (2009) Managing food production systems for resilience. In Principles of Ecosystem Stewardship: Resilience-Based Natural Resource Management in a Changing World (Chapin, F.S., III et al., eds), 259-280, Springer

35. Chapin, F.S., III et al. (2000) Consequences of changing biotic diversity. Nature 405, $234-242$

36. Díaz, S. et al. (2007) Incorporating plant functional diversity effects in ecosystem service assessments. Proc. Natl. Acad. Sci. USA 104, 20684-20689

37. Folke, C. et al. (2004) Regime shifts, resilience, and biodiversity in ecosystem management. Anпu. Rev. Ecol. Syst. 35, 557-581

38. McLachlan, J.S. et al. (2007) A framework for debate of assisted migration in an era of climate change. Conserv. Biol. 21, 297-302

39. Colding, J. et al. (2006) Locally managed green areas as part of urban ecosystem management. Ambio 35, 237-244

40. Kristjanson, P. et al. (2009) Linking international agricultural research knowledge with action for sustainable development. Proc. Natl. Acad. Sci. USA 106, 5047-5052

41. Maffi, L. (2005) Linguistic, cultural and biological diversity. Annu. Rev. Anthropol. 29, $599-617$

42. Scott, J.C. (1998) Seeing like a State: How Certain Schemes to Improve the Human Condition Have Failed. Yale University Press 
43. Nettle, D., and Romaine, S. (2000) Vanishing Voices: The Extinction of the World's Languages. Oxford University Press

44. Putnam, R.D. (2007) E Pluribus Unam: Diversity and community in the twenty-first century. Scand. Polit. Stud. 30,137-174

45. Armitage, D. et al., eds (2007) Adaptive Co-Management: Collaboration, Learning, and Multi-Level Governance. University of British Columbia Press

46. Social Learning Group. (2001) Learning to Manage Global Environmental Risks. vols. 1, 2. MIT Press

47. Epstein, M.J. (2008) Making Sustainability Work: Best Practices in Managing and Measuring Corporate Social, Environmental, and Economic Impacts. Greenleaf Publishing Ltd 48. Carpenter, S.R. et al. (2006) Scenarios for ecosystem services: An overview. Ecol. Soc. 11, http://www.ecologyandsociety.org/vol11/iss11/art29/

49. Postel, S.L., and Richter, B. (2003) Rivers for Life: Managing Water for People and Nature. Island Press

50. Swanson, F.J., and Chapin, F.S., III (2009) Forest Systems: Living with long-term change. In Principles of Ecosystem Stewardship: Resilience-Based Natural Resource Management in a Changing World (Chapin, F.S., III, et al., eds), 149-170, Springer

51. Bormann, B.T., and Kiester, A.R. (2004) Options forestry: Acting on uncertainty. J. For. $102,22-27$

52. Young, M., and McColl, J. (2008) A future-proofed basin: A new water management regime for the Murray-Darling Basin. In Droplet 13, University of Adelaide 53. Burton, I. et al. (1993) The Environment as Hazard. 2nd edition. Guilford 54. Andersson, K. et al. (2009) Local Governments and Rural Development: Comparing Lessons from Brazil, Chile, Mexico and Peru. University of Arizona Press 
55. Agrawal, A. et al. (2008) Changing governance of the world's forests. Science $320,1460-1462$

56. Olsson, P. et al. (2004) Social-ecological transformation for ecosystem management: The development of adaptive co-management of a wetland landscape in southern Sweden. Ecol. Soc. 9, http://www.ecologyandsociety.org/vo19/iss4/art2/

57. Kaiser, R.B. et al. (2008) Leadership and the fate of organizations. Amer. Psychol. 63, 96-110

58. Olsson, P. et al. (2004) Social-ecological transformation for ecosystem management: The development of adaptive co-management of a wetland landscape in southern Sweden. Ecol. Soc. 9, [online] www.ecologyandsociety.org/vol9/iss4/art2

59. Westley, F. et al. (2002) Why systems of nature and people are not just social and ecological systems. In Panarchy: Understanding Transformations in Human and Natural Systems (Gunderson, L.H., and Holling, C.S., eds), 103-120, Island Press

60. Carpenter, S.R., and Brock, W.A. (2008) Adaptive capacity and traps. Ecol. Soc. 13, 40. [online] URL: http://www.ecologyandsociety.org/vol13/iss42/art40/

61. Galaz, V. et al. (2008) The problem of fit among biophysical systems, environmental and resource regimes, and broader governance systems: Insights and emerging challenges. In Institutions and Environmental Change: Principal Findings, Applications, and Research Frontiers (Young, O.R., et al., eds), 147-186, MIT Press

62. Olsson, P. et al. (2008) Navigating the transition to ecosystem-based management of the Great Barrier Reef, Australia. Proc. Natl. Acad. Sci. USA 105, 9489-9494 
63. Loorbach, D., and Rotmans, J. (2006) Managing transitions for sustainable development. In Understanding Industrial Transformation: Views from Different Disciplines (Olshoorn, X., and Wieczorek, A.J., eds), http://hdl.handle.net/1765/7630, Springer

64. Bardach, E. (2008) A Practical Guide to Policy Analysis: The Eightfold Path to More Effective Problem Solving. 3rd edition. CQ Press

65. Peterson, G.D. et al. (2003) Scenario planning: A tool for conservation in an uncertain world. Conserv. Biol. 17, 358-366

66. Ginn, W.J. (2005) Investing in Nature: Case Studies of Land Conservation in Collaboration with Business. Island Press

67. Kates, R.W. et al. (2006) Reconstruction of New Orleans after Hurricane Katrina: A research perspective. Proc. Natl. Acad. Sci. USA 103, 14653-14660

68 Olsson, P. et al. (2006) Shooting the rapids: Navigating transitions to adaptive governance of social-ecological systems. Ecol. Soc. 11, 18. [online] URL: http://www.ecologyandsociety.org/vol11/iss11/art18/

69. Betsill, M.M., and Corell, E., eds (2007) NGO Diplomacy: The Influence of Nongovernmental Organizations in International Environmental Negotiations. MIT Press 70. Young, O.R. (2002) The Institutional Dimensions of Environmental Change: Fit, Interplay, and Scale. MIT Press

71. Berkman, P.A., and Young, O.R. (2009) Governance and environmental change in the Arctic Ocean. Science 324, 339-340

72. Cash, D.W. et al. (2006) Scale and cross-scale dynamics: governance and information in a multilevel world. Ecol. Soc. 11, 8

73. Rockström, J. et al. 2009. A safe operating space for humanity. Nature 461, 472-475 
74 WCED. (1987) Our Common Future. World Commission on Environment and Development, Oxford University Press 


\section{Glossary $^{8}$}

Adaptive capacity: Capacity of social-ecological systems, including both their human and ecological components, to respond to, create, and shape variability and change in the state of the system.

Ecosystem services: the benefits that society derives from ecosystems.

Ecosystem stewardship: A strategy to respond to and shape social-ecological systems under conditions of uncertainty and change to sustain the supply and opportunities for use of ecosystem services to support human well-being.

Human well-being: Quality of life in terms of material needs, freedom and choice, good social relations, and personal security.

Resilience: Capacity of a social-ecological system to absorb a spectrum of shocks or perturbations and to sustain and develop its fundamental function, structure, identity, and feedbacks as a result of recovery or reorganization in a new context.

Sustainability: Use of the environment and resources to meet the needs of the present without compromising the ability of future generations to meet their needs ${ }^{74}$.

Transformation: Fundamental change in a social-ecological system resulting in different controls over system properties, new ways of making a living, and often changes in scales of critical feedbacks. Transformations can be purposefully navigated or unintended.

Vulnerability: Degree to which a system is likely to experience harm due to exposure and sensitivity to a specified hazard or stress and its adaptive capacity to respond to the stress. 
Table 1. Differences between steady-state resource management and ecosystem stewardship.

\begin{tabular}{|l|l|l|}
\hline Characteristic & $\begin{array}{l}\text { Steady-State Resource } \\
\text { Management }\end{array}$ & Ecosystem Stewardship \\
\hline Reference point & Historic condition & Trajectory of change \\
\hline Central goal & Ecological integrity & $\begin{array}{l}\text { Sustain social-ecological } \\
\text { systems and delivery of } \\
\text { ecosystem services }\end{array}$ \\
\hline Predominant approach & $\begin{array}{l}\text { Manage resource stocks and } \\
\text { condition }\end{array}$ & $\begin{array}{l}\text { Manage stabilizing and } \\
\text { amplifying feedbacks }\end{array}$ \\
\hline Role of uncertainty & $\begin{array}{l}\text { Reduce uncertainty before } \\
\text { taking action }\end{array}$ & $\begin{array}{l}\text { Embrace uncertainty: } \\
\text { Maximize flexibility to adapt } \\
\text { to an uncertain future }\end{array}$ \\
\hline Role of research & $\begin{array}{l}\text { Researchers transfer } \\
\text { findings to managers who } \\
\text { take action }\end{array}$ & $\begin{array}{l}\text { Researchers and managers } \\
\text { collaborate through adaptive } \\
\text { management to create } \\
\text { continuous learning loops }\end{array}$ \\
\hline Role of resource manager & Decision maker who sets & $\begin{array}{l}\text { Facilitator who engages } \\
\text { stakeholder groups to respond } \\
\text { to and shape social-ecological } \\
\text { change and nurture resilience }\end{array}$ \\
\hline & Minimize disturbance & Disturbance cycles used to \\
\hline
\end{tabular}




\begin{tabular}{|c|c|c|}
\hline & probability and impacts & $\begin{array}{l}\text { provide windows of } \\
\text { opportunity }\end{array}$ \\
\hline $\begin{array}{l}\text { Resources of primary } \\
\text { concern }\end{array}$ & $\begin{array}{l}\text { Species composition and } \\
\text { ecosystem structure }\end{array}$ & $\begin{array}{l}\text { Biodiversity, well-being, and } \\
\text { adaptive capacity }\end{array}$ \\
\hline
\end{tabular}


Box 1. Ecosystem or Societal Sustainability?

Broadly speaking, two threads of literature have contributed to sustainability concepts. One comes from ecology and addresses ecological sustainability as a basis for biodiversity conservation. The other comes from geography and United Nations development efforts and addresses socio-economic sustainability of human well-being ${ }^{11,74}$. Following the lead of the Millennium Ecosystem Assessment, we integrate these approaches to address social-ecological sustainability, recognizing that people are integral components of social-ecological systems and that people both affect and respond to ecosystem processes ${ }^{3,7,8}$. Failure to address the synergies and tradeoffs between ecological and societal well-being are unlikely to be successful. Local inhabitants, for example, are unlikely to respect rules that establish parks for species conservation but exclude local people and reduce their livelihood opportunities ${ }^{9,40}$. Conversely, development projects that stimulate unintended ecosystem degradation (e.g. illegal logging due to improved access) are unlikely to produce a sustainable trajectory of human well-being ${ }^{3}$. 
Box 2. Examples of strategies to reduce vulnerability to known stresses.

Vulnerability theory has developed with a focus on practical outcomes ${ }^{11-13}$. It has been the basis for assessing impacts and planning adaptation actions to address climate change and other known hazards and stresses ${ }^{17,26,30}$. Broad strategies are generally well proven, but implementation varies with local context.

Reduce exposure to hazards and stresses

- Minimize known stresses and avoid or minimize novel hazards and stresses

- Develop new institutions that minimize global-scale stresses

- Manage in the context of projected changes rather than historical range of variability Reduce social-ecological sensitivities and adapt to adverse impacts

- Sustain the capacity of ecosystems to provide multiple ecosystem services

- Sustain and enhance critical components of well-being, particularly of vulnerable segments of society

- Plan sustainable development to address the tradeoffs among costs and benefits for ecosystems, multiple segments of today's society, and future generations 
Box 3. Examples of stewardship strategies to prepare for and shape uncertain change.

Resilience theory addresses the likelihood that systems will persist in the face of uncertain shocks and perturbations ${ }^{14-16}$. Theoretical expectations of resilience theory are well developed, and its application to practical problems is currently being assessed ${ }^{7,8,36}$.

Maintain a diversity of options

- Subsidize innovations that foster socio-economic novelty and diversity

- Renew the functional diversity of degraded systems

- Prioritize conservation of biodiversity hotspots and pathways that enable species to adjust to rapid environmental change

- Sustain a diversity of cultures, languages, and knowledge systems that provide multiple approaches to meeting societal goals.

Enhance social learning to facilitate adaptation

- Broaden the problem definition and knowledge co-production by engaging multiple disciplinary perspectives and knowledge systems

- Use scenarios and simulations to explore consequences of alternative policy options

- Develop transparent information systems and mapping tools that contribute to developing trust among decision makers and stakeholders, and build support for action

- Test understanding through comparative analysis, experimentation, and adaptive management

- Exercise extreme caution in experiments that perturb a system larger than the jurisdiction of management 
Adapt governance to implement potential solutions

- Provide an environment for leadership and respect to develop

- Foster social networking that builds trust and bridges communication and accountability among existing organizations

- Permit sufficient overlap in responsibility among organizations to allow redundancy in policy implementation 
Box 4. Strategies for transforming from traps to potentially more favorable trajectories.

Transformation is urgently needed to address degradation in ecosystem services and human wellbeing. Hypotheses have been advanced regarding factors that facilitate or impede transformation, but the underlying theory and empirical evidence are only beginning to be assembled ${ }^{19,60-63,68}$.

Preparing for transformation

- Engage stakeholders to identify dysfunctional states and raise awareness of problems

- Identify thresholds, plausible alternative states, pathways, and triggers

- Identify the barriers to change, potential change agents, and strategies to overcome barriers

Navigating the transition

- Identify potential crises and use them as opportunities to initiate change

- Maintain flexible strategies and transparency

- Foster institutions that facilitate cross-scale and cross-organizational interactions and stakeholder participation

Building resilience of the new regime

- Create incentives and foster values for stewardship in the new context

- Initiate and mobilize social networks of key individuals for problem-solving

- Foster interactions and support of decision makers at other levels 


\section{Figure legends.}

Fig. 1. Evolution of resource-management regimes observed in many western nations ${ }^{11}$. Arrows at the bottom show the management time course for selected locations. Dashed arrows show opportunities for developing nations to "leap-frog" from current management directly to ecosystem stewardship. The red-to-green gradient represents increased sustainability.

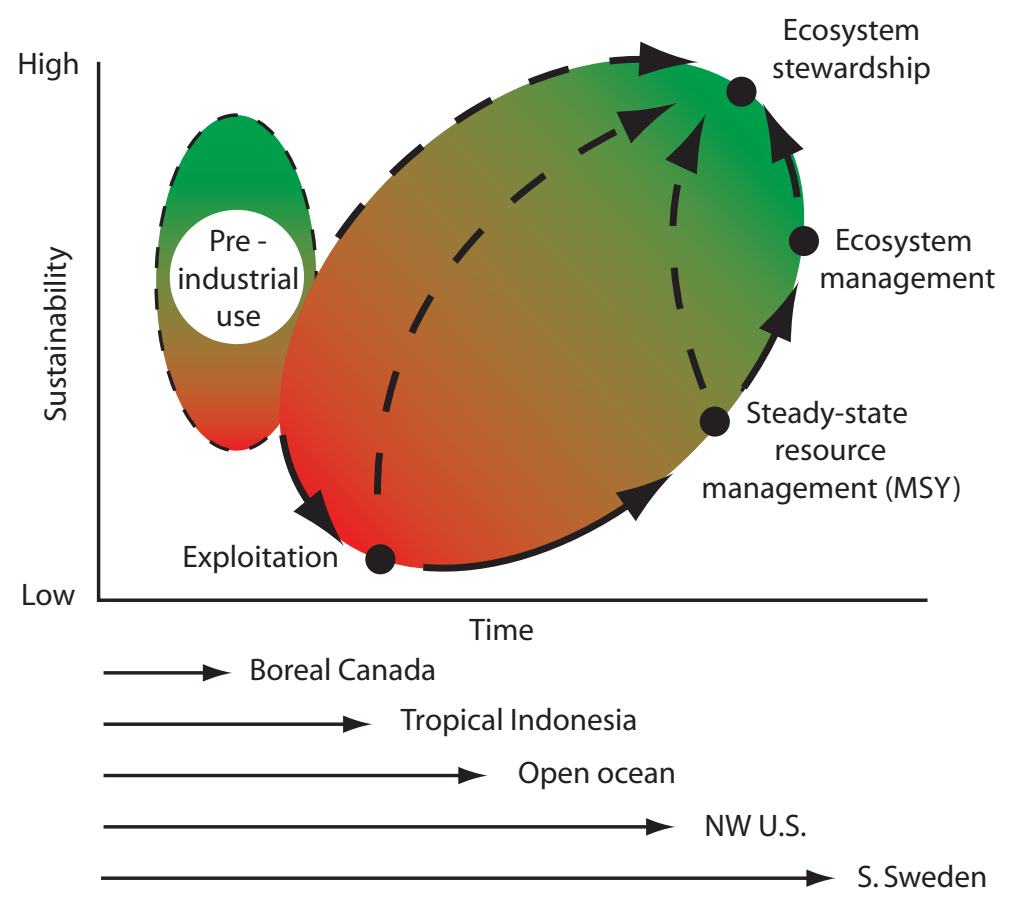


Fig. 2. Application of the ecosystem stewardship framework ${ }^{8,11}$ to the impact and response of New Orleans to Hurricane Katrina ${ }^{67}$. A suite of external stresses (land subsidence from wetland drainage and increased hurricane intensity associated with warming) interact to create impacts (loss of life and property). Social learning (learning, coping, innovating, and adapting) in response to these impacts has the potential to alter social-ecological interactions and various forms of capital of the system (New Orleans, the blue box), which in turn influence sensitivity to future events. Social learning also governs the relative likelihood of three potential outcomes: persistence of the existing system through resilience; actively navigated transformation to a new, potentially more beneficial trajectory through transformation; or unintended degradation to a new state due to vulnerability and failure to adapt or transform. Photographs come from the following sources: hurricane (geology.com/news/labels/Hurricane-Katrina.html), New Orleans flood (http://mulattodiaries.wordpress.com/2009/08/29/four-years-ago/), New Orleans community meeting (ttp://www.9thwardnena.org/home), wetlands (agreenliving.org/tag/unitedstates/), and levee rebuilding (http://blog.nola.com/news_impact/2009/05/large_levee1.jpg). 


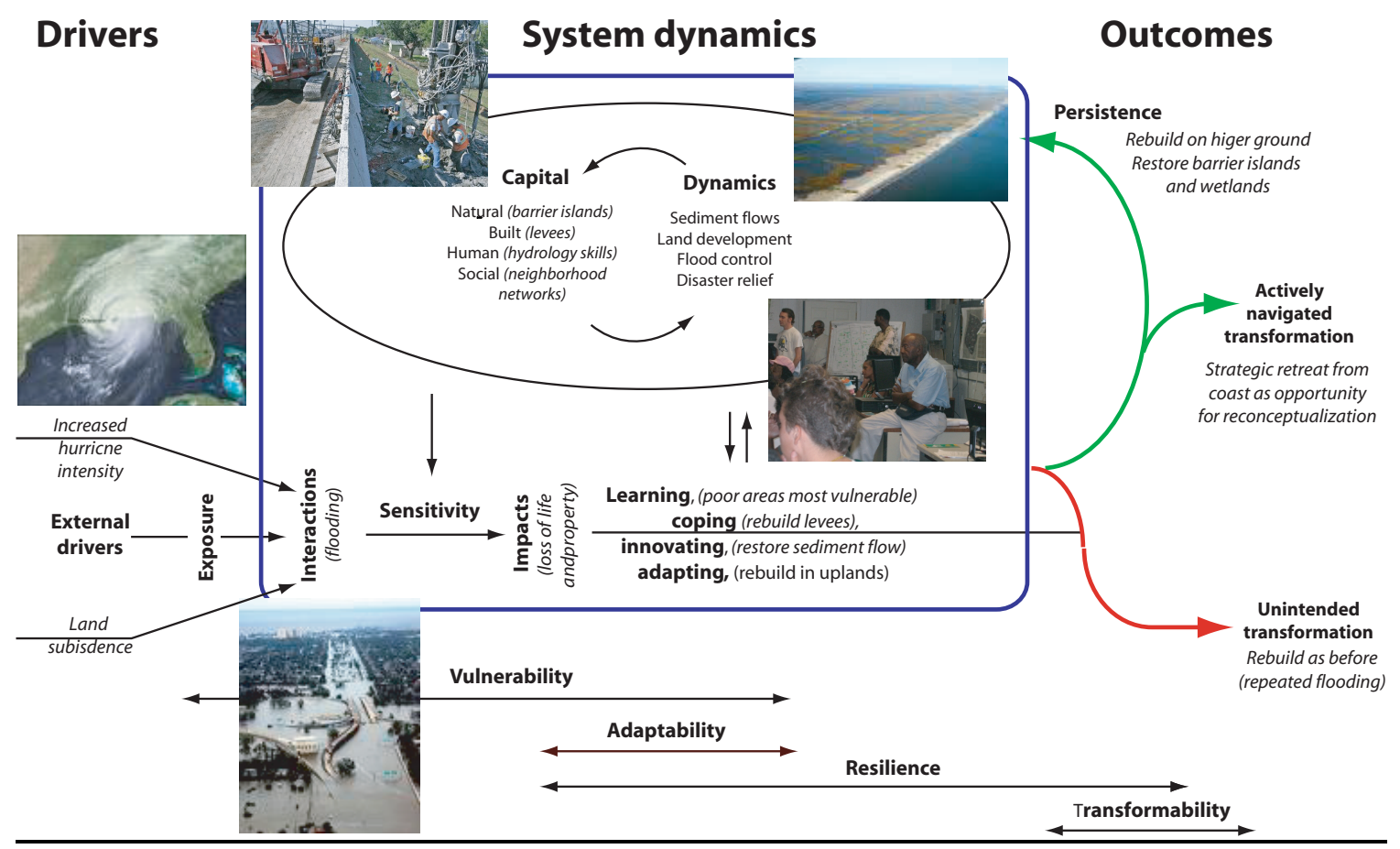

